\title{
Bioclimatic Predictors for Supporting Ecological Applications in the Conterminous United States
}

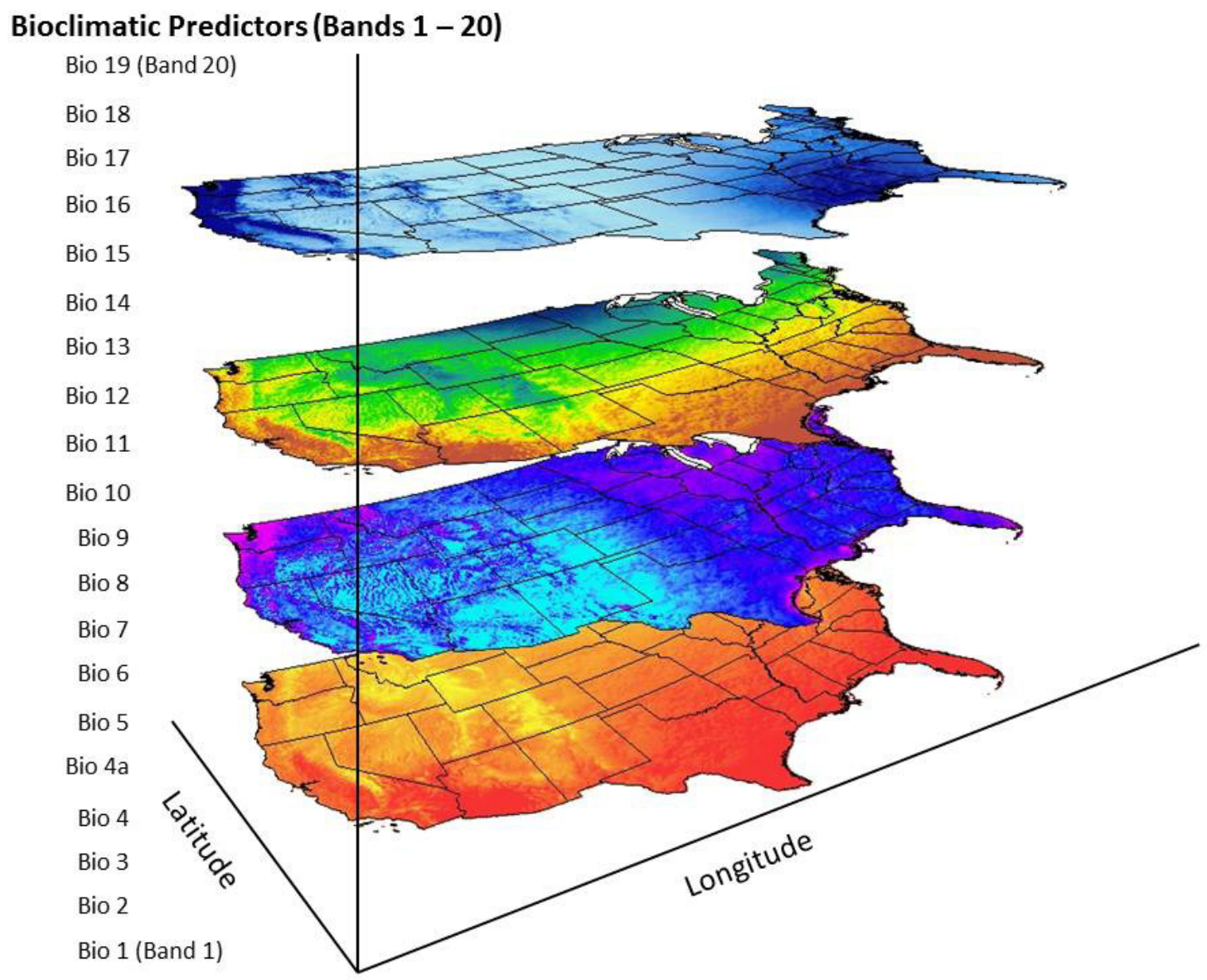

Data Series 691

U.S. Department of the Interior

U.S. Geological Survey 



\section{Bioclimatic Predictors for Supporting Ecological Applications in the Conterminous United States}

By Michael S. O'Donnell and Drew A. Ignizio

Data Series 691 


\title{
U.S. Department of the Interior \\ KEN SALAZAR, Secretary \\ U.S. Geological Survey \\ Marcia K. McNutt, Director
}

\author{
U.S. Geological Survey, Reston, Virginia: 2012
}

For more information on the USGS - the Federal source for science about the Earth, its natural and living resources, natural hazards, and the environment, visit http://www.usgs.gov or call 1-888-ASK-USGS.

For an overview of USGS information products, including maps, imagery, and publications, visit http://www.usgs.gov/pubprod

To order this and other USGS information products, visit http://store.usgs.gov

Any use of trade, product, or firm names is for descriptive purposes only and does not imply endorsement by the U.S. Government.

Although this information product, for the most part, is in the public domain, it also contains copyrighted materials as noted in the text. Permission to reproduce copyrighted items must be secured from the copyright owner.

Suggested citation:

O'Donnell, M.S., and Ignizio, D.A., 2012, Bioclimatic predictors for supporting ecological applications in the conterminous United States: U.S. Geological Survey Data Series 691, 10 p. 


\section{Contents}

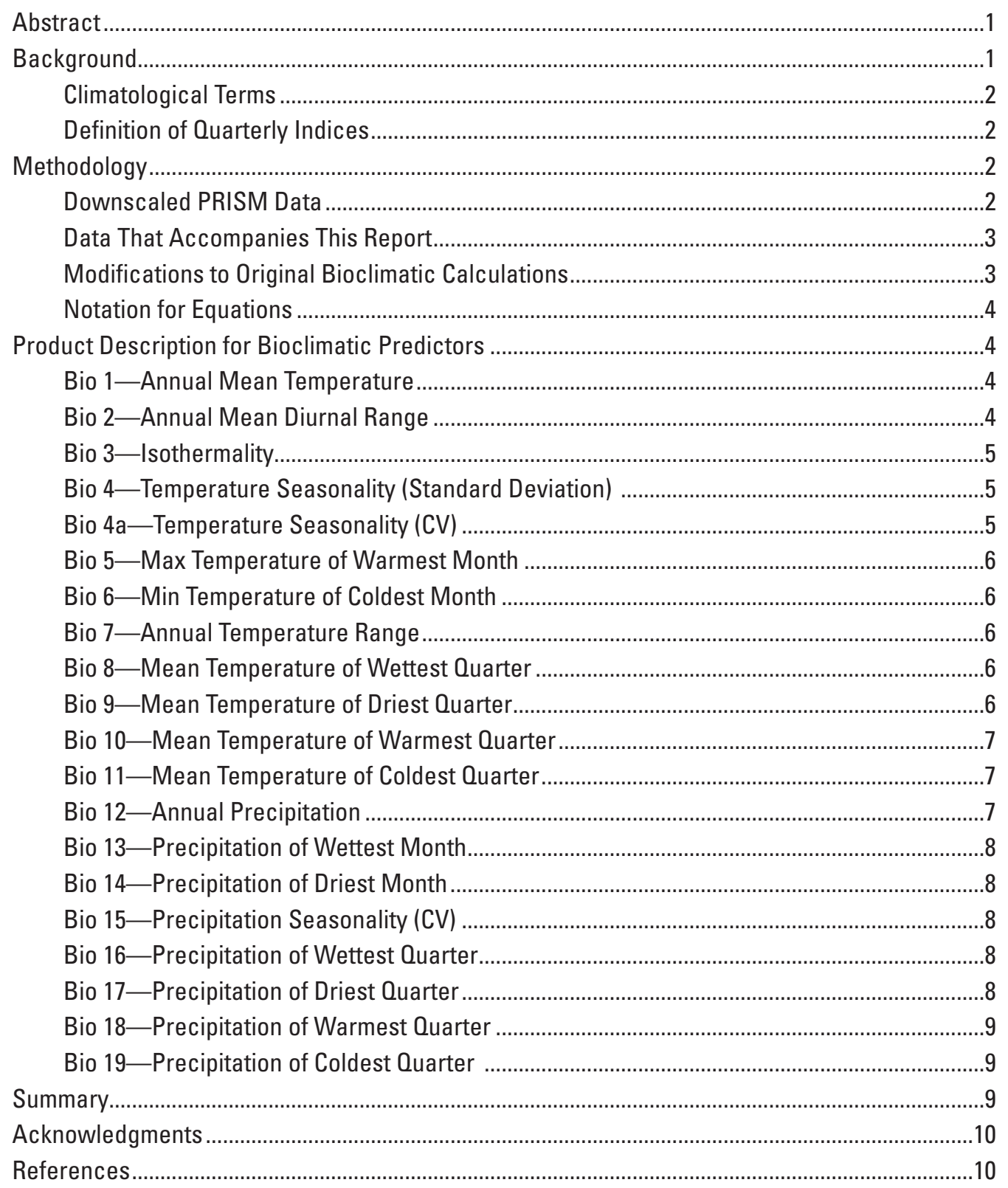

\section{Tables}

1. Climate data inputs used to derive the bioclimatic predictors for the conterminous

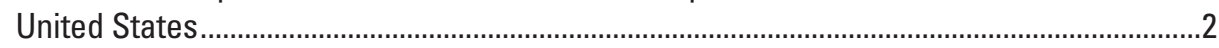

2. Data series file naming convention .......................................................................................

3. Example of applying quarterly calculations to normals and time-series climate data.........4 


\section{Conversion Factors}

\begin{tabular}{|c|c|c|}
\hline Multiply & By & To obtain \\
\hline \multicolumn{3}{|c|}{ Length } \\
\hline inch (in.) & 25.4 & millimeter (mm) \\
\hline foot $(\mathrm{ft})$ & 0.3048 & meter $(\mathrm{m})$ \\
\hline \multicolumn{3}{|l|}{ SI to Inch/Pound } \\
\hline Multiply & By & To obtain \\
\hline \multicolumn{3}{|c|}{ Length } \\
\hline millimeter $(\mathrm{mm})$ & 0.03937 & inch (in.) \\
\hline meter (m) & 3.281 & foot (ft) \\
\hline kilometer (km) & 0.6214 & mile (mi) \\
\hline
\end{tabular}

Temperature in degrees Celsius $\left({ }^{\circ} \mathrm{C}\right)$ may be converted to degrees Fahrenheit $\left({ }^{\circ} \mathrm{F}\right)$ as follows:

$$
{ }^{\circ} \mathrm{F}=\left(1.8 \times{ }^{\circ} \mathrm{C}\right)+32
$$

Temperature in degrees Fahrenheit $\left({ }^{\circ} \mathrm{F}\right)$ may be converted to degrees Celsius $\left({ }^{\circ} \mathrm{C}\right)$ as follows:

$$
{ }^{\circ} \mathrm{C}=\left({ }^{\circ} \mathrm{F}-32\right) / 1.8
$$

Temperature in degrees Celsius $\left({ }^{\circ} \mathrm{C}\right)$ may be converted to degrees Kelvin $\left({ }^{\circ} \mathrm{K}\right)$ as follows:

$$
{ }^{\circ} \mathrm{K}={ }^{\circ} \mathrm{C}+273.15
$$

Temperature in degrees Fahrenheit $\left({ }^{\circ} \mathrm{F}\right)$ may be converted to degrees Kelvin $\left({ }^{\circ} \mathrm{K}\right)$ as follows:

$$
{ }^{\circ} \mathrm{K}=\left({ }^{\circ} \mathrm{F}+459.67\right) / 1.8
$$

Horizontal coordinate information is referenced to the North American Datum of 1983 (NAD 83) and the World Geographic System of 1972 (WGS 72). 


\title{
Bioclimatic Predictors for Supporting Ecological Applications in the Conterminous United States
}

\author{
By Michael S. O'Donnell' and Drew A. Ignizio²
}

\section{Abstract}

The U.S. Geological Survey (USGS) has developed climate indices, referred to as bioclimatic predictors, which highlight climate conditions best related to species physiology. A set of 20 bioclimatic predictors were developed as Geographic Information Systems (GIS) continuous raster surfaces for each year between 1895 and 2009. The Parameterelevation Regression on Independent Slopes Model (PRISM) and down-scaled PRISM data, which included both averaged multi-year and averaged monthly climate summaries, was used to develop these multi-scale bioclimatic predictors. Bioclimatic predictors capture information about annual conditions (annual mean temperature, annual precipitation, annual range in temperature and precipitation), as well as seasonal mean climate conditions and intra-year seasonality (temperature of the coldest and warmest months, precipitation of the wettest and driest quarters). Examining climate over time is useful when quantifying the effects of climate changes on species distributions for past, current, and forecasted scenarios. These data, which have not been readily available to scientists, can provide biologists and ecologists with relevant and multi-scaled climate data to augment research on the responses of species to changing climate conditions. The relationships established between species demographics and distributions with bioclimatic predictors can inform land managers of climatic effects on species during decisionmaking processes.

\section{Background}

Species are affected by both climatic and non-climatic factors. Climatic change can impose physiological constraints on species and therefore can affect species distributions to varying degrees. The relationship between climate and the distribution of a species throughout a landscape varies due to local adaptation and other factors, such as dispersion constraints related to habitat availability.

${ }^{1}$ U.S. Geological Survey

${ }^{2}$ Cherokee Services Group, Fort Collins, Colo.
Bioclimatic predictors (as defined by Nix, 1986 and Hijmans, 2004) were derived from two climate data sources (Climate Source, 2011; Oregon State University, 2011) to better represent the types of seasonal trends pertinent to the physiological constraints of different species. For example, wettest month and seasonal anomalies will generally capture broader biological trends better than the temperature or the amount of precipitation for a given day due to the inherent variability associated with weather. Some of these variables are potentially multicollinear (more prominent at local regions), and therefore, caution is advised when including multiple bioclimatic predictors within species distribution models.

The 20 bioclimatic predictors were derived using an open source programming language, Python $^{\circledR}$, which is based on the Environmental Systems Research Institute's (ESRI) Arc Macro Language $\left(\mathrm{AML}^{\circledR}\right)$ program written by Robert Hijmans (2004). The input data are in the geographic coordinate system latitude/longitude and rely on two datums (table 1). To minimize introducing errors while projecting these data from latitude/longitude to a map projection, which can introduce errors resulting from the distortions associated with the selected map projections and data characteristics (for example, scale, heterogeneity), the bioclimatic variables remain in the climate data's native coordinate system. However, in most analysis scenarios, these data will need to be converted to a map projection.

Due to the volume of data, the data's spatial extent (conterminous United States), the spatial resolution, and the temporal resolution, we used High Throughput Computing (HTC) via the Condor middleware (http://research.cs.wisc.edu/condor/) to distribute the processing tasks. For example, each set of 20 bioclimatic predictors ( 20 products are derived for each year) require the development of approximately 200 interim datasets for a total of 576,000 datasets to obtain the final derived products. As a result, we were able to reduce the level of processing time by using high throughput computing. All climate data inputs required conversion to GIS data formats (native climate data is stored in ASCII format), conversion of units (accounts for scale factors used to compress data), assignment of a defined coordinate system, and the importation and editing of metadata for the final product. We then developed multi-band GeoTiff raster datasets (table 2) where each of the 20 bioclimatic 
Table 1. Climate data inputs used to derive the bioclimatic predictors for the conterminous United States.

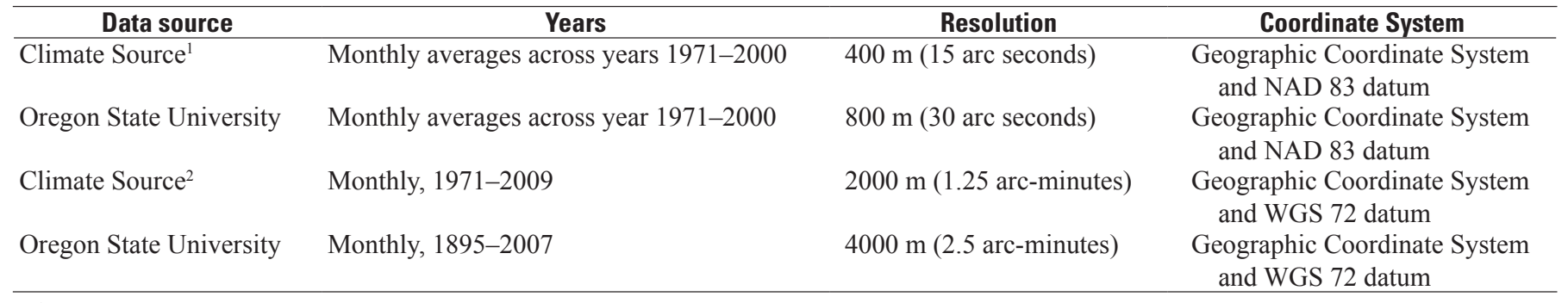

${ }^{1}$ Climate Source downscaled the Oregon State University PRISM $800 \mathrm{~m}$ climate data.

${ }^{2}$ Climate Source downscaled the Oregon State University PRISM 4 km climate data.

variables for a given year was represented as a different band. The process for developing the multi-band bioclimatic predictor raster datasets is discussed within this document as well as the accompanying Federal Geographic Data Committee (FGDC) metadata (http://www.fgdc.gov/metadata).

\section{Climatological Terms}

Climate normals are 30-year monthly averaged temperature and precipitation data between 1971 and 2000 (30 years inclusive).

Climate time-series are monthly data for each year. That is to say the years are not averaged over a 30-year span as with the climate normals data.

The maximum temperature (Tmax) and minimum temperature (Tmin) for monthly data reflect the monthly means of daily maximum temperatures and monthly means of daily minimum temperatures. Tmax and Tmin can define either a single month for a specific year (time-series) or the mean of a single month across a span of years (normals).

The total monthly precipitation (PPT) defines the total precipitation for a single month within a specific year (timeseries) or it is defined as the monthly mean total precipitation of a single month across a span of years (normals).

\section{Definition of Quarterly Indices}

Quarterly indices are based on 3 month intervals. For each month, the two subsequent months are evaluated. To produce indices at the end of the year, the quarterly period is defined using the months in the beginning of the year (when using climate normals). For example, if December is the target month, then January and February of the same averaged time period are included in the quarter. When time-series climate data is evaluated, we have permitted the quarterly period to extend across two years. The exception to this description is when we are evaluating the final year for time-series data. When the latter scenario occurs, we will use months within the same year. Hijmans (2004) does not include months from subsequent years (time-series), but rather uses months from the beginning of the same year. We believe the $\mathrm{AML}^{\circledR}$ was intended to be used on normals climate data and not timeseries climate data. Our analysis has been adapted to handle both time-series and normals climate data.

In the unlikely event that the same precipitation/ temperature was recorded for different quarters (constituting a quarterly tie), precipitation/temperature data will be selected from the first chronological quarter. This applies for quarterly bioclimatic variables, which identify and summarize the wettest, driest, warmest, and coldest periods of the year.

\section{Methodology}

\section{Downscaled PRISM Data}

PRISM is an analytical model that uses point data and a digital elevation model (DEM) to generate gridded estimates of monthly temperature and monthly total precipitation. PRISM is well suited to regions with mountainous terrain, because it incorporates a conceptual framework that addresses the spatial scale and pattern of orographic processes (Daly and Phillips, 1994). To improve upon the $4 \mathrm{~km}$ and $800 \mathrm{~m}$ PRISM data that were developed by the Climate Group at Oregon State University, Climate Source applied a Gaussian filter, which was a modification of the Barnes filter (Barnes, 1964), to increase the resolution of the original grids from the base resolution of $4 \mathrm{~km}$ to $2 \mathrm{~km}$ (time-series) and $800 \mathrm{~m}$ to $400 \mathrm{~m}$ (normals).

Table 2. Data series file naming convention.

[One dataset exists for Composites_400m and one dataset exists for Composites_800m. The dataset filenames for the $2 \mathrm{~km}$ and $4 \mathrm{~km}$ data will denote a different year for each dataset]

\begin{tabular}{cl}
\hline Root folder & \multicolumn{1}{c}{ Example dataset name } \\
\hline Composites_400m & BioClimComposite_1971_2000_400m.tif \\
Composites_800m & BioClimComposite_1971_2000_800m.tif \\
Composites_2km & BioClimComposite_(Year)_2km.tif \\
Composites_4km & BioClimComposite_(Year)_4km.tif \\
\hline
\end{tabular}


Prior to interpolation, the gridded surface is first resampled to one-half the $\mathrm{x}$ - and $\mathrm{y}$-distance of its original resolution ( $4 \mathrm{~km}$ to $2 \mathrm{~km}$ and $800 \mathrm{~m}$ to $400 \mathrm{~m}$ ), hereafter referred to as half-resolution. The re-sampled grid is then shifted the distance of its half-resolution in both the $\mathrm{x}$ - and $\mathrm{y}$-directions, such that the center of every third cell in the shifted half-resolution grid falls directly over a node (or corner) of original input data. The filter then interpolates the shifted half-resolution grid from the original grid by calculating a distance weighted average from neighboring grid cells. The resampled cell values thus come from those pixel values of the underlining original grid that fall within the boundary of the shifted halfresolution grid.

The following cases were considered when deriving the surface using the Gaussian filter. When the shifted halfresolution grid is equidistant from four original input grid cells (that is, over a node), then the four original cells are averaged to create the new downscaled grid cell. If the shifted halfresolution grid cell falls completely within an original grid cell, the downscaled grid cell is assigned the same value as the original grid cell. In the case of calculating the value of a new downscaled grid cell where the shifted half-resolution grid cells falls between two original grid cells at the same longitude or latitude, then the two adjacent original grid cells are averaged to create the downscaled grid cell.

The Climate Source downscaling approach does not add new features to the spatial patterns in the original grid; rather, it simply interpolates between existing grid cells using Gaussian-weighted averaging to produce a higher resolution grid that preserves local detail.

\section{Data That Accompanies This Report}

A suite of GIS raster datasets (GeoTiff), which are available for download accompany this report. Each raster dataset is a multiband composite that includes 20 bioclimatic variables (20 bands within each composite raster dataset). The bioclimatic variables are derived from $400 \mathrm{~m}$ and $800 \mathrm{~m}$ resolution climate normals (table 1), and $2 \mathrm{~km}$ and $4 \mathrm{~km}$ resolution climate time-series (table 1). Each dataset consists of a world file (.tfw), an FGDC metadata file (.xml), a pyramids overview file (.ovr), an auxiliary file (.aux.xml), a summary statistics file (.aux.xml) and a GeoTiff file (.tif). Users only require the GeoTiff file, but auxiliary files are provided for metadata, faster rendering display time (which is the purpose of overview file), and dataset summary statistics (aux.xml). These data are organized and bundled in zip compression files for download within each of the four bioclimatic composite folders (Composites_400m, Composites_800m, Composites_2km, and Composites_4km). The composite folders for the $400 \mathrm{~m}$ and $800 \mathrm{~m}$ bioclimatic data contain a single zip file. The $2 \mathrm{~km}$ and $4 \mathrm{~km}$ time-series data contain multiple zip files that bundle a range of years. For instance, users will find a zip file called Composites_2km_1980_1989. zip, which contains ten composite raster datasets (one for each year) of the $2 \mathrm{~km}$ resolution derived bioclimatic variables.

The authors scrutinized these data carefully using several methods. We first evaluated each bioclimatic predictor to determine that the output correctly represented the resolution and information relevant to the predictor in question (based on definitions outlined within this document). Second, we wrote a script that flagged datasets where values assigned to pixels fell outside a typical range. For example, any bioclimatic variables describing temperature and that did not fall within the U.S. temperature extremes $\left(-66.7^{\circ} \mathrm{C}\right.$ and $\left.57^{\circ} \mathrm{C}\right)$ where highlighted as a potential error. Any bioclimatic variables describing precipitation were flagged as a potential error when values fell outside of the range of $0 \mathrm{~mm}$ and $9000 \mathrm{~mm}$. If the bioclimatic predictor represented a percentage, we flagged any datasets that produced results greater than 100 percent. The datasets that were flagged using this method were investigated to ensure that pixel values were not a result of mis-calculating the bioclimatic predictor, but rather a result of the input data. We explain within this document (for example, see Bio 15 description) why this might occur (where it pertains to a bioclimatic predictor) and where these anomalies typically occur (spatially).

\section{Modifications to Original Bioclimatic Calculations}

Several minor modifications to the original $\mathrm{AML}^{\circledR}$ written by Robert Hijmans (posted on the Bioclim website; http://www.worldclim.org/bioclim) were implemented to derive these data products. We also added one bioclimatic variable to the original 19 that Hijmans developed. The modifications were as follows:

1. The original $\mathrm{AML}^{\circledR}$ multiplies the result of Bio 4 (Temperature Seasonality) by 100 , which appears to have been applied to preserve significant digits for some other application. Our data does not multiply this result by 100 .

2. We do not round data inputs or outputs (that is, data inputs are floating point to the degree that the source data accuracy is preserved).

3. Quarterly indices are based on running 3-month intervals (much like a running sum). For each month, the two subsequent months are evaluated. When time-series climate data are evaluated, we have permitted the quarterly period to extend across two years. The exception to this is when we are evaluating the final year for time-series data. When this occurs, we will use months within the same year. Similarly, when working with climate normals, at the end of the year the quarterly period is defined using the months in the beginning of the year. An example of applying a quarterly measurement to climate normals and climate time-series data is provided in table 3. 
4. The $\mathrm{AML}^{\circledR}$ calculates temperature seasonality (referred to as Bio 4 in this report) using the standard deviation of the mean monthly temperature instead of deriving the temperature seasonality coefficient of variation. The standard deviation was used instead of the coefficient of variation because degrees Fahrenheit and degrees Celsius may have negative values and the coefficient of variation is not interpretable under these circumstances. Also, if the mean temperature is zero, the coefficient of variation cannot be calculated (that is, you cannot divide by zero). Although we provide the original temperature seasonality bioclimatic predictor (standard deviation), as outlined by Hijmans, we also converted temperature to degrees Kelvin and calculated temperature seasonality using the coefficient of variation. This additional bioclimatic variable is included in the data and referred to as Bio 4a.

5. Metadata was dynamically developed for all derived products with the use of metadata templates. For each dataset, parameters unique to the GIS data were extracted from that specific dataset and inserted into the template to produce a unique metadata record.

6. Detailed documentation on the methods used for deriving these products is provided, which had not been published by the original developers.

\section{Notation for Equations}

i $\quad=$ month

$\operatorname{Tmax}=$ monthly mean of daily maximum temperatures $\left({ }^{\circ} \mathrm{C}\right)$

$\operatorname{Tmin}=$ monthly mean of daily minimum temperatures $\left({ }^{\circ} \mathrm{C}\right)$

Tavgi $=\left(\frac{\operatorname{Tmax}_{i}+\operatorname{Tmin}_{i}}{2}\right)$ is the average temperature

$\left({ }^{\circ} \mathrm{C}\right)$ for the given month $(i)$.

TKmax $=$ monthly mean of daily maximum temperatures $\left({ }^{\circ} \mathrm{K}\right)$

TKmin = monthly mean of daily minimum temperatures $\left({ }^{\circ} \mathrm{K}\right)$

$\operatorname{Tkavg}_{i}=$ the average temperature $\left({ }^{\circ} \mathrm{K}\right)$ for the given month $(i)$.

$P P T=$ total monthly precipitation $(\mathrm{mm})$

$\sum_{i=1}^{i=12} \quad$ is the summation of a climate measurement across all months within a given year (e.g., Jan., Feb., ..., Dec.).

$\sum_{i=12}^{i=2} \quad$ is the summation of a climate measurement for months of December in year 1, January in year 2, and February in year 2. These calculations are used for the quarterly indices described below (see also: table 3).
Table 3. Example of applying quarterly calculations to normals and time-series climate data.

[Normals data are averaged climate indices of a single month across multiple years. For example, precipitation is averaged across all January measurements to produce a single measurement that represents January 1971-2009. Calculating the quarterly for normals data that occurs during December requires using January and February data averaged across 1971-2009. Quarterlies calculated for timeseries data do not use normalized monthly indices and therefore these quarterlies are calculated using monthly climate data from subsequent years. For example, quarterlies calculated for December require monthly data across two different years. The example below shows the data inputs that would be used to calculate a quarterly index for normals data (for the time period 1971-2009), and for timeseries data (for December, 2000).]

\begin{tabular}{ll}
\hline \multicolumn{1}{c}{ Normals } & \multicolumn{1}{c}{ Time-series } \\
\hline December, 1971-2009 & December, 2000 \\
January, 1971-2009 & January, 2001 \\
February, 1971-2009 & February, 2001 \\
\hline
\end{tabular}

\section{Product Description for Bioclimatic Predictors}

\section{Bio 1-Annual Mean Temperature}

- Definition: The annual mean temperature.

- Units: Degrees Celsius

- Data Inputs: The average temperature for each month $\left(\right.$ Tavg $\left._{\mathrm{i}}\right)$

- Calculation:

$$
\text { Bio } 1=\frac{\sum_{i=1}^{i=12} \operatorname{Tavg}_{i}}{12}
$$

The climate inputs are averaged across the year to acquire the annual mean temperature. We calculate the average temperature for each month, and then average these results over twelve months.

- Interpretation: The annual mean temperature approximates the total energy inputs for an ecosystem.

\section{Bio 2-Annual Mean Diurnal Range}

- Definition: The mean of the monthly temperature ranges (monthly maximum minus monthly minimum). Since the climate data inputs are monthly or averaged months across multiple years, this calculation uses recorded temperature fluctuation within a month to capture diurnal temperature range. Using monthly averages in this manner is mathematically equivalent to calculating the temperature range for each day in a month, and averaging these values for the month.

- Units: Degrees Celsius

- Data Inputs: Monthly maximum temperatures $\left({ }^{\circ} \mathrm{C}\right)$ and monthly minimum temperatures $\left({ }^{\circ} \mathrm{C}\right)$ 
- Calculation:

$$
\text { Bio } 2=\frac{\sum_{i=1}^{i=12}\left(\operatorname{Tmax}_{i}-\operatorname{Tmin}_{i}\right)}{12}
$$

- Each monthly diurnal range is the difference between that month's maximum and minimum temperature. This difference is then averaged over the twelve months of the year.

- Interpretation: This index can help provide information pertaining to the relevance of temperature fluctuation for different species.

\section{Bio 3-Isothermality}

- Definition: Isothermality quantifies how large the dayto-night temperatures oscillate relative to the summerto-winter (annual) oscillations.

- Units: Percent

- Data Inputs: Results from equation 2 and equation 8

- Calculation:

$$
\text { Bio } 3=\frac{\text { Bio } 2}{\text { Bio } 7} x 100
$$

Isothermality is derived by calculating the ratio of the mean diurnal range (Bio 2) to the annual temperature range (Bio 7, discussed below), and then multiplying by 100 .

- Interpretation: Isothermality is generally useful for tropical, insular, and maritime environments (Nix, 1986). Isothermality quantifies how large the day-tonight temperatures oscillate relative to the summerto-winter (annual) oscillations. An isothermal value of 100 indicates the diurnal temperature range is equivalent to the annual temperature range, while anything less than 100 indicates a smaller level of temperature variability within an average month relative to the year. A species distribution may be influenced by larger or smaller temperature fluctuations within a month relative to the year and this predictor is useful for ascertaining such information.

\section{Bio 4-Temperature Seasonality (Standard Deviation)}

- Definition: The amount of temperature variation over a given year (or averaged years) based on the standard deviation (variation) of monthly temperature averages.

- Units: Temperature (degrees Celsius)

- Data Inputs: The average temperature for each month $\left(\right.$ Tavg $\left._{\mathrm{i}}\right)$
- Calculation:

$$
\text { Bio } 4=S D\left\{\operatorname{Tavg}_{1}, \ldots, \text { Tavg }_{12}\right\}
$$

The standard deviation of the 12 mean monthly temperature values is calculated. The original $\mathrm{AML}^{\circledR}$ multiplies the result by 100 , which was designed to preserve significant digits, but in our calculations we do not do multiply by 100 .

- Interpretation: Temperature seasonality is a measure of temperature change over the course of the year. The $\mathrm{AML}^{\circledR}$ developed by Robert Hijmans and posted on Bioclim (http://www.worldclim.org/bioclim) calculates temperature seasonality using the standard deviation of the mean monthly temperature instead of deriving the temperature seasonality coefficient of variation. The larger the standard deviation, the greater the variability of temperature.

\section{Bio 4a-Temperature Seasonality (CV)}

- Definition: The amount of temperature variation over a given period based on the ratio of the standard deviation of the monthly mean temperatures to the mean monthly temperature (also known as the coefficient of variation $(\mathrm{CV}))$.

- Units: Percent

- Data Inputs: The average temperature for each month $\left(\right.$ Tavg $\left._{i}\right)$ and the annual mean temperature in ${ }^{\circ} \mathrm{K}$ (Bio 1).

- Calculation:

$$
\text { Bio } 4 a=\frac{S D\left\{\text { Tkavg }_{1}, \ldots, \text { Tkavg }_{12}\right\}}{(\text { Bio 1 } 1+273.15)} x 100
$$

For this calculation, temperature values are converted to degrees Kelvin so negative temperatures values do not occur and it avoids the possibility of having to divide by zero. $\mathrm{CV}$ is calculated by first averaging the minimum temperature and maximum temperature values for each month. Then the standard deviation of the 12 mean monthly temperature values is calculated. We then divide the standard deviation by the mean monthly temperature (Bio 1 in ${ }^{\circ} \mathrm{K}$ ) and multiply this by 100 .

- Interpretation: Temperature seasonality is a measure of temperature change over the course of the year. The temperature Coefficient of Variation (CV) is the ratio of the standard deviation of the monthly mean temperatures to the mean of the monthly temperatures (also known as the relative standard deviation) and is expressed as a percentage. CV therefore captures the dispersion in relative terms because standard deviation can produce two similar values while the means may be different. However, if variance is the same, an area with a lower mean temperature is distinguishable from an area with similar variance but with a higher mean temperature. The larger the percentage, the greater the variability of temperature. 


\section{Bio 5-Max Temperature of Warmest Month}

- Definition: The maximum monthly temperature occurrence over a given year (time-series) or averaged span of years (normal).

- Units: Degrees Celsius

- Data Inputs: Monthly maximum temperatures $\left({ }^{\circ} \mathrm{C}\right)$

- Calculation:

$$
\text { Bio } 5=\max \left(\left\{\operatorname{Tmax}_{1}, \ldots, \operatorname{Tmax}_{12}\right\}\right)
$$

This is calculated by selecting the maximum temperature value across all months within a given year.

- Interpretation: This information is useful when examining whether species distributions are affected by warm temperature anomalies throughout the year.

\section{Bio 6-Min Temperature of Coldest Month}

- Definition: The minimum monthly temperature occurrence over a given year (time-series) or averaged span of years (normal).

- Units: Degrees Celsius

- Data Inputs: Monthly minimum temperatures $\left({ }^{\circ} \mathrm{C}\right)$

- Calculation:

$$
\text { Bio } 6=\min \left(\left\{\operatorname{Tmin}_{1}, \ldots, \operatorname{Tmin}_{12}\right\}\right)
$$

This is calculated by selecting the minimum temperature value across all months within a given year.

- Interpretation: This information is useful when examining whether species distributions are affected by cold temperature anomalies throughout the year.

\section{Bio 7-Annual Temperature Range}

- Definition: A measure of temperature variation over a given period.

- Units: Degrees Celsius

- Data Inputs: Results from equation 6 and equation 7

- Calculation:

$$
\text { Bio } 7=\text { Bio } 5-\text { Bio } 6
$$

This is calculated by subtracting Bio 6 (Minimum Temperature of Coldest Month) from Bio 5 (Maximum Temperature of Warmest Month).

- Interpretation: This information is useful when examining whether species distributions are affected by ranges of extreme temperature conditions.

\section{Bio 8-Mean Temperature of Wettest Quarter}

- Definition: This quarterly index approximates mean temperatures that prevail during the wettest season.

- Units: Degrees Celsius
- Data Inputs: The average temperature and the total precipitation for each month

- Calculation:

$$
Q_{P P T \max }=\max \left(\left|\begin{array}{c}
\sum_{i=1}^{i=3} P P T_{i}, \\
\sum_{i=2}^{i=4} P P T_{i}, \\
\ldots, \\
\sum_{i=10}^{i=12} P P T_{i} \\
\sum_{i=1}^{i=1} P P T_{i} \\
\sum_{i=12}^{i=2} P P T_{i}
\end{array}\right|\right)\left\{\begin{array}{l}
\text { Where precipitation is } \\
\text { evaluated for 12 consecutive } \\
\text { sets of 3 months. The last } \\
\text { two sets span two years for } \\
\text { time-series data }
\end{array}\right.
$$

Bio $8=\frac{\sum_{i=1}^{i=3} \operatorname{Tavg}_{i}}{3}\left\{\begin{array}{l}\text { Where monthly temperature } \\ \text { averages are based on the } \\ \text { three selected months of } Q_{\text {PPTmax }}\end{array}\right.$

To calculate this bioclimatic predictor we first identify the three consecutive months with the highest cumulative precipitation total. In the unlikely event that the exact same amount of precipitation was recorded for two different quarters (constituting a quarterly tie for maximum precipitation), temperature data will be taken from the quarter that comes first chronologically. We then calculate the average temperature for the three months with the highest cumulative precipitation.

- Interpretation: This index provides mean temperatures during the wettest three months of the year, which can be useful for examining how such environmental factors may affect species seasonal distributions.

\section{Bio 9-Mean Temperature of Driest Quarter}

- Definition: This quarterly index approximates mean temperatures that prevail during the driest quarter.

- Units: Degrees Celsius

- Data Inputs: The average temperature and the total precipitation for each month

- Calculation:

$\left.Q_{P P T \min }=\min \left(\begin{array}{c}\sum_{i=1}^{i=3} P P T_{i}, \\ \sum_{i=2}^{i=4} P P T_{i}, \\ \ldots, \\ \sum_{i=10}^{i=12} P P T_{i} \\ \sum_{i=11}^{i=1} P P T_{i} \\ \sum_{i=12}^{i=2} P P T_{i}\end{array} \mid\right) \mid \begin{array}{l}\text { Where precipitation is } \\ \text { evaluated for 12 consecutive } \\ \text { sets of 3 months. The last } \\ \text { two sets span two years for } \\ \text { time-series data }\end{array}\right)$ Bio $9=\frac{\sum_{i=1}^{i=3} \operatorname{Tavg}_{i}}{3}\left\{\begin{array}{l}\text { Where monthly temperature } \\ \text { averages are based on the } \\ \text { three selected months of } Q_{P P T \text { min }}\end{array}\right.$ 
To calculate this bioclimatic predictor we first identify the three consecutive months with the lowest cumulative precipitation total. In the unlikely event that the exact same amount of precipitation was recorded for two different quarters (constituting a quarterly tie for minimum precipitation), temperature data will be taken from the quarter that comes first chronologically. We then calculate the average temperature for the three months with the lowest cumulative precipitation.

- Interpretation: This index provides mean temperatures during the driest three months of the year, which can be useful for examining how such environmental factors may affect species seasonal distributions.

\section{Bio 10-Mean Temperature of Warmest Quarter}

- Definition: This quarterly index approximates mean temperatures that prevail during the warmest quarter.

- Units: Degrees Celsius

- Data Inputs: The average temperature for each month

- Calculation:

$Q_{\text {Tmax }}=\max \left(\left|\begin{array}{c}\sum_{i=1}^{i=3} \text { Tavg }_{i}, \\ \sum_{i=2}^{i=4} \text { Tavg }_{i}, \\ \ldots, \\ \sum_{i=10}^{i=12} \text { Tavg }_{i} \\ \sum_{i=11}^{i=1} \text { Tavg }_{i} \\ \sum_{i=12}^{i=2} \text { Tavg }_{i}\end{array}\right|\right) \mid \begin{aligned} & \text { Where temperatures are } \\ & \text { evaluated for 12 } \text { consecutive } \\ & \text { sets of } 3 \text { months. The last } \\ & \text { two sets span two years for } \\ & \text { time-series data }\end{aligned}$

Bio $10=\frac{\sum_{i=1}^{i=3} \operatorname{Tavg}_{i}}{3}\left\{\begin{array}{l}\text { Where monthly temperature } \\ \text { averages are based on the } \\ \text { three selected months of } Q_{T \max }\end{array}\right.$

To calculate this bioclimatic predictor we first identify the warmest quarter of the year (the average temperatures of each month in the quarter are summed; the quarter with the highest value is selected). If quarterly ties occur, the first chronological quarter is selected as the warmest quarter. We then calculate the average temperature for the three months in the warmest quarter.

- Interpretation: This index provides mean temperatures during the warmest three months of the year, which can be useful for examining how such environmental factors may affect species seasonal distributions.

\section{Bio 11-Mean Temperature of Coldest Quarter}

- Definition: This quarterly index approximates mean temperatures that prevail during the coldest quarter.

- Units: Degrees Celsius

- Data Inputs: The average temperature for each month

- Calculation:

$Q_{T \min }=\min \left(\left|\begin{array}{c}\sum_{i=1}^{i=3} \text { Tavg }_{i}, \\ \sum_{i=2}^{i=4} \text { Tavg }_{i}, \\ \ldots, \\ \sum_{i=10}^{i=12} \text { Tavg }_{i} \\ \sum_{i=1}^{i=1} \text { Tavg }_{i}, \\ \sum_{i=12}^{i=2} \text { Tavg }_{i}\end{array}\right|\right)\left\{\begin{array}{l}\text { Where temperatures are } \\ \text { evaluated for 12 consecutive } \\ \text { sets of } 3 \text { months. The last } \\ \text { two sets span two years for } \\ \text { time-series data }\end{array}\right.$

Bio $11=\frac{\sum_{i=1}^{i=3} \operatorname{Tavg}_{i}}{3}\left\{\begin{array}{l}\text { Where monthly temperature } \\ \text { averages are based on the } \\ \text { three selected months of } Q_{\text {Tmin }}\end{array}\right.$

To calculate this bioclimatic predictor we first identify the coolest quarter of the year (the average temperatures of each month in the quarter are summed; the quarter with the lowest value is selected). If quarterly ties occur, the first chronological quarter is selected as the coolest quarter. We then calculate the average temperature for the three months in the coldest quarter.

- Interpretation: This index provides mean temperatures during the coldest three months of the year, which can be useful for examining how such environmental factors may affect species seasonal distributions.

\section{Bio 12-Annual Precipitation}

- Definition: This is the sum of all total monthly precipitation values.

- Units: Millimeters

- Data Inputs: Total precipitation for each month

- Calculation:

$$
\text { Bio } 12=\sum_{i=1}^{i=12} P P T_{i}
$$

To calculate this bioclimatic predictor we sum the precipitation values of each of the 12 months in a year.

- Interpretation: Annual total precipitation approximates the total water inputs and is therefore useful when ascertaining the importance of water availability to a species distribution. 


\section{Bio 13-Precipitation of Wettest Month}

- Definition: This index identifies the total precipitation that prevails during the wettest month.

- Units: Millimeters

- Data Inputs: Total precipitation for each month

- Calculation:

$$
\text { Bio } 13=\max \left(\left[P P T_{i}, \ldots, P P T_{12}\right]\right)
$$

To calculate this bioclimatic predictor we identify the month with the highest cumulative precipitation total.

- Interpretation: The wettest month is useful if extreme precipitation conditions during the year influence a species potential range.

\section{Bio 14—Precipitation of Driest Month}

- Definition: This index identifies the total precipitation that prevails during the driest month.

- Units: Millimeters

- Data Inputs: Total precipitation for each month

- Calculation:

$$
\text { Bio } 14=\min \left(\left[P P T_{i}, \ldots, P P T_{12}\right]\right)
$$

To calculate this bioclimatic predictor we identify the month with the lowest cumulative precipitation total.

- Interpretation: The driest month is useful if extreme precipitation conditions during the year influence a species potential range.

\section{Bio 15-Precipitation Seasonality (CV)}

- Definition: This is a measure of the variation in monthly precipitation totals over the course of the year. This index is the ratio of the standard deviation of the monthly total precipitation to the mean monthly total precipitation (also known as the coefficient of variation) and is expressed as a percentage.

- Units: Percent

- Data Inputs: Total monthly precipitation for each month

- Calculation:

$$
\text { Bio } 15=\frac{S D\left\{P P T_{1}, \ldots, P P T_{12}\right\}}{1+(\text { Bio } 12 / 12)} x 100
$$

To derive this bioclimatic predictor we first calculate the standard deviation of the 12 monthly precipitation totals. We then divide this result by the mean monthly precipitation value. One is added to the denominator to avoid strange $\mathrm{CV}$ values where mean rainfall is less than 1. Lastly, we multiply the result by 100 .
- Interpretation: Since species distributions can be strongly influenced by variability in precipitation, this index provides a percentage of precipitation variability where larger percentages represent greater variability of precipitation. CV therefore captures the dispersion in relative terms because standard deviation can produce two similar values while the means may be different. However, if variance is the same, an area with smaller mean is distinguishable from other areas with similar variance but with a larger mean. The larger the percentage, the greater the variability of precipitation. We noticed that in some regions the $\mathrm{CV}$ values exceeded 100 percent. These regions were investigated and we determined that in these areas the variance (standard deviation) of the precipitation throughout the year exceeded the average precipitation. Most likely this can be explained by precipitation anomalies (or errors introduced by the original PRISM models) throughout the course of the year in these regions. These rare occurrences seem mostly isolated to coastal areas and islands.

\section{Bio 16-Precipitation of Wettest Quarter}

- Definition: This quarterly index approximates total precipitation that prevails during the wettest quarter.

- Units: Millimeters

- Data Inputs: Total precipitation for each month

- Calculation:

Bio $16=\max \left(\mid \begin{array}{c}\sum_{i=1}^{i=3} P P T_{i}, \\ \sum_{i=2}^{i=4} P P T_{i} \\ \ldots, \\ \sum_{i=12}^{i=12} P P T_{i} \\ \sum_{i=1}^{i=1} P P T_{i} \\ \sum_{i=12}^{i=2} P P T_{i}\end{array},\right)\left\{\begin{array}{l}\text { Where precipitation is } \\ \text { evaluated for 12 consecutive } \\ \text { sets of 3 months. The last } \\ \text { two sets span two years for } \\ \text { time-series data }\end{array}\right)$

To derive this bioclimatic predictor we first identify the three consecutive months with the highest cumulative precipitation total and then we sum the precipitation values for all three months. If quarterly ties occur, the first chronological quarter is selected as the wettest quarter.

- Interpretation: This index provides total precipitation during the wettest three months of the year, which can be useful for examining how such environmental factors may affect species seasonal distributions.

\section{Bio 17-Precipitation of Driest Quarter}

- Definition: This quarterly index approximates total precipitation that prevails during the driest quarter.

- Units: Millimeters

- Data Inputs: Total precipitation for each month 
- Calculation:

Bio $17=\min \left(\left|\begin{array}{c}\sum_{i=1}^{i=3} P P T_{i} \\ \sum_{i=2}^{i=4} P P T_{i} \\ \ldots, \\ \sum_{i=10}^{i=12} P P T_{i} \\ \sum_{i=11}^{i=1} P P T_{i} \\ \sum_{i=12}^{i=2} P P T_{i}\end{array}\right|\right) \begin{aligned} & \text { Where precipitation is } \\ & \text { evaluated for 12 consecutive } \\ & \text { sets of 3 months. The last } \\ & \text { two sets span two years for } \\ & \text { time-series data }\end{aligned}$

To derive this bioclimatic predictor we first identify the three consecutive months with the lowest cumulative precipitation total and then we sum the precipitation values for all three months. If quarterly ties occur, the first chronological quarter is selected as the driest quarter.

- Interpretation: This index provides total precipitation during the driest three months of the year, which can be useful for examining how such environmental factors may affect species seasonal distributions.

\section{Bio 18-Precipitation of Warmest Quarter}

- Definition: This quarterly index approximates total precipitation that prevails during the warmest quarter.

- Units: Millimeters

- Data Inputs: The average temperature and the total precipitation for each month

- Calculation:

$$
Q_{\text {Tmax }}=\max \left(\left|\begin{array}{c}
\sum_{i=1}^{i=3} \text { Tavg }_{i}, \\
\sum_{i=2}^{i=4} \text { Tavg }_{i}, \\
\ldots, \\
\sum_{i=10}^{i=12} \text { Tavg }_{i} \\
\sum_{i=11}^{i=1} \text { Tavg }_{i}, \\
\sum_{i=12}^{i=2} \text { Tavg }_{i}
\end{array}\right|\right) \mid \begin{aligned}
& \text { Where temperatures are } \\
& \text { evaluated for 12 consecutive } \\
& \text { sets of } 3 \text { months. The last } \\
& \text { two sets span two years for } \\
& \text { time-series data }
\end{aligned}
$$

Bio $18=\sum_{i=1}^{i=3} \operatorname{PPT}_{i}\left\{\begin{array}{l}\text { Where monthly precipitation } \\ \text { values are based on the } \\ \text { three selected months of } Q_{T \max }\end{array}\right.$

To calculate this bioclimatic predictor we first identify the warmest quarter of the year (the average temperatures of each month in the quarter are summed; the quarter with the highest value is selected). If quarterly ties occur, the first chronological quarter is selected as the warmest quarter. The precipitation values for the three months in this quarter are then summed.

- Interpretation: This index provides total precipitation during the warmest three months of the year, which can be useful for examining how such environmental factors may affect species seasonal distributions.

\section{Bio 19—Precipitation of Coldest Quarter}

- Definition: This quarterly index approximates total precipitation that prevails during the coldest quarter.

- Units: Millimeters

- Data Inputs: The average temperature and the total precipitation for each month

- Calculation:

$Q_{\text {Tmin }}=\min \left(\left|\begin{array}{c}\sum_{i=1}^{i=3} \text { Tavg }_{i}, \\ \sum_{i=2}^{i=4} \text { Tavg }_{i}, \\ \ldots, \\ \sum_{i=10}^{i=12} \text { Tavg }_{i} \\ \sum_{i=11}^{i=1} \text { Tavg }_{i} \\ \sum_{i=12}^{i=2} \text { Tavg }_{i}\end{array}\right|\right) \mid \begin{aligned} & \text { Where temperatures are } \\ & \text { evaluated for } 12 \text { consecutive } \\ & \text { sets of } 3 \text { months. The last } \\ & \text { two sets span two years for } \\ & \text { time-series data }\end{aligned}$

Bio $19=\sum_{i=1}^{i=3} \operatorname{PPT}_{i}\left\{\begin{array}{l}\text { Where monthly precipitation } \\ \text { values are based on the } \\ \text { three selected months of } Q_{\text {Tmin }}\end{array}\right.$

To calculate this bioclimatic predictor we first identify the coldest quarter of the year (the average temperatures of each month in the quarter are summed; the quarter with the lowest value is selected). If quarterly ties occur, the first chronological quarter is selected as the lowest quarter. The precipitation values for the three months in this quarter are then summed.

- Interpretation: This index provides total precipitation during the coldest three months of the year, which can be useful for examining how such environmental factors may affect species seasonal distributions.

\section{Summary}

The bioclimatic data series provides GIS continuous raster surfaces that represent multiple temporal and spatial resolutions. The source climate datasets permitted us to produce bioclimatic predictors for multiple scales $(400 \mathrm{~m}, 800 \mathrm{~m}$, $2 \mathrm{~km}, 4 \mathrm{~km}$ ) and normalized/time-series climate summaries (averaged climate indices between 1971-2009 and monthly averaged climate indices between 1895-2007). Therefore, the bioclimatic predictors provide derived climate metrics of biological relevance for researchers and land managers to understand species responses to climate change. Because the input data used to generate these products are based on climate models and the outputs represent summaries of climate data at coarse resolutions, they should be used for regional assessments and general trends. Users should also be cognizant of how the climate models were produced (PRISM and downscaled PRISM (Climate Source)) and the limitations these models may have for a specific application. 


\section{Acknowledgments}

Funding for this project was provided by the U.S. Geological Survey, Fort Collins Science Center. We would also like to thank one of our reviewers, Travis Schmidt, whose comments greatly improved the organization of this document.

\section{References}

Barnes, S.L., 1964, A technique for maximizing details in numerical weather map analysis: Journal of Applied Meteorology, v. 3, p. 396-409.

Climate Source, Inc, 2011, Downscaled OSU PRISM climate data: Corvallis, Oreg., The Climate Source. Available at http://www.climatesource.com/.
Daly, Christopher, Neilson, Ronald P., and Phillips, Donald L., 1994, A statistical-topographic model for mapping climatological precipitation over mountainous terrain: Journal of Applied Meteorology v. 33, p. 140-158.

Hijmans, Robert J., 2004, Arc Macro Language (AML ${ }^{\circledR}$ ) version 2.1 for calculating 19 bioclimatic predictors: Berkeley, Calif, Museum of Vertebrate Zoology, University of California at Berkeley. Available at http://www.worldclim.org/bioclim.

Nix, Henry A., 1986, A biogeographic analysis of Australian elapid snakes, in Longmore, Richard, ed., Atlas of elapid snakes of Australia: Canberra, Australian Flora and Fauna Series 7, Australian Government Publishing Service, p. 4-15.

The PRISM Climate Group, 2011, Parameter-elevation Regression on Independent Slopes Model (PRISM): Corvallis, Oreg, Oregon State University. Available at http://www.prism.oregonstate.edu/.

Publishing support provided by:

Denver Publishing Service Center

For more information concerning this publication, contact:

Center Director, USGS Fort Collins Science Center

2150 Centre Ave., Bldg. C

Fort Collins, C0 80526-8118

(970) 226-9398

Or visit the Fort Collins Science Center Web site at:

http://www.fort.usgs.gov/

This report is available at: http://pubs.usgs.gov/ds/691 


$$
\text { 造 }
$$

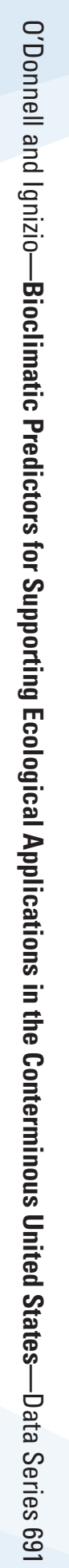

